\title{
Espaço-tempo de confinamento no Oeste francês: estatísticas, mapas, impressões
}

Espaço-tempo de confinamento no Oeste francês: estatísticas, mapas, impressões Espace-temps de confinement dans l'Ouest de la France: des statistiques, des cartes, des impressions

Espacio-tiempo de confinamiento en el oeste francés: estadísticas, mapas, impresiones

Space-Time of confinement in the French West: statistics, maps and impressions.

\section{Alexandre Queiroz Pereira}

\section{(2) OpenEdition} Journals

Edição electrónica

URL: http://journals.openedition.org/espacoeconomia/11962

DOI: 10.4000/espacoeconomia.11962

ISSN: 2317-7837

Editora

Núcleo de Pesquisa Espaço \& Economia

Refêrencia eletrónica

Alexandre Queiroz Pereira, « Espaço-tempo de confinamento no Oeste francês: estatísticas, mapas, impressões », Espaço e Economia [Online], 18| 2020, posto online no dia 16 abril 2020, consultado o 20 maio 2020. URL : http://journals.openedition.org/espacoeconomia/11962 ; DOI : https://doi.org/ 10.4000/espacoeconomia.11962

Este documento foi criado de forma automática no dia 20 maio 2020.

(c) NUPEE 


\section{Espaço-tempo de confinamento no Oeste francês: estatísticas, mapas, impressões}

Espaço-tempo de confinamento no Oeste francês: estatísticas, mapas, impressões Espace-temps de confinement dans l'Ouest de la France: des statistiques, des cartes, des impressions

Espacio-tiempo de confinamiento en el oeste francés: estadísticas, mapas, impresiones

Space-Time of confinement in the French West: statistics, maps and impressions.

Alexandre Queiroz Pereira

Agradecimentos

$O$ autor agradece aos financiamentos dos projetos CAPES PGPSE Proc. 88887.123947/2016-00: Sistemas Ambientais costeiros e ocupação econômica do Nordeste; CAPES PRINT Proc. 88887.312019/2018-00: Integrated socio-environmental technologies and methods for territorial sustainability: alternatives for local communities in the context of climate change, Bolsa de Professor Visitante Junior, e Programa CAPES/FUNCAP Proc. 88887.165948/2018-00: Apoio às Estratégias de Cooperação Científica do Programa de Pós-Graduação em Geografia - UFC.

\section{Introdução}

1 Na história estão registradas pestes, epidemias e pandemias, tais como peste bubônica no século XIV; cólera no XIX; varíola e tuberculose no XIX-XX; gripe espanhola, tifo, febre amarela, sarampo, malária e ebola no XX. Variam o local da disseminação, os transmissores e o número de mortes, porém as mudanças derivadas são sempre catastróficas e capazes de provocar efeitos colaterais na política, na economia e na cultura. O que essas experiências históricas e trágicas nos ensinaram?

Em texto datado de 2004 intitulado Teorias médicas e gestão urbana: a seca de $1877-79 \mathrm{em}$ Fortaleza, a professora Clélia Costa esclarece como as doenças eram pensadas no século 
XIX, de que forma os doentes eram tratados e os graves problemas gerados nas cidades - sobretudo nas mais pobres. Ela explica ainda a relação entre a varíola, a estiagem e as graves desigualdades sociais no Ceará, especialmente em Fortaleza. À época, os confinamentos forçados dos mais pobres nos abarracamentos foi a principal solução tomada e recaiu sobre um quantitativo próximo a vinte e sete mil famílias. Ao refinar o estado da arte, Costa enfatiza o papel e o poder do discurso médico higienista no ordenamento da sociedade e dos espaços, principalmente as cidades (COSTA, 2013; 2014). Na segunda década do século XXI, o discurso médico tornar-se-á predominante na regulação do cotidiano de massas urbanas? Outros profissionais e suas teses e estratégias ganharão destaque? ${ }^{1}$

3 No ano de 2020, para todos os países e sociedades, o desafio é o vírus SARS-CoV-2 e a doença derivada, COVID-19. Se pensarmos friamente, sobretudo pelo conhecimento já acumulado, há razões para estranhar a surpresa pela qual a pandemia de COVID-19 é noticiada e sentida. Primeiro, os vírus do tipo corona há tempos são conhecidos pelos pesquisadores - basta lembrar as síndromes respiratórias aguda grave (SARS) e a do Oriente Médio (MERS), ambas correlacionadas a esta família viral. Segundo, desde janeiro, na província chinesa de Wuhan e, em seguida, em outras cidades e países do sudeste asiático, verificou-se a velocidade de contaminação e o percentual de casos que evoluíam para estados graves. Terceiro, Milton Santos, ainda nos anos 1990, tratava a unicidade das técnicas e do tempo como característica-chave para pensar o contemporâneo e alcançar os efeitos do processo de globalização.

Esta unicidade não se constitui sem fluxos e estes, e as redes, são fotografias do modo de vida urbano-regional-internacional do qual usufruimos para comprar, viajar, vender, produzir e comunicar ${ }^{2}$. Certamente, na contemporaneidade o sentido etimológico da palavra pandemia ${ }^{3} g a n h a$, de fato, condições empíricas de realização.

5 À luz tanto de fatos quanto de especulações, autores mundialmente reconhecidos se pronunciaram ao analisar o momento e a difusão da COVID-19. Noam Chomsky teme a escalada das formas de autoritarismo. Mike Davis descreve a gravidade da situação para as classes sociais mais pobres por causa do enfraquecimento dos sistemas públicos de saúde. Por sua vez, David Harvey cita o abalo do sistema de consumo de rápida rotatividade. A impotência e a paralisia do Estado frente às crises é destacada por Bruno Latour. Domenico de Masi e Manuel Castells impressionam-se com as condições da Itália e da Espanha. A partir de outra perspectiva, Byung-Chul Han compara a ação dos países europeus com a dos principais países asiáticos sublinhando diferenças na organização sociocultural, política e tecnológica. Mais otimista frente a mudanças radicais, Slavoj Zizek menciona um possível "golpe” fatal no capitalismo e a reinvenção do comunismo ${ }^{4}$.

6 Neste sentido, nossa pretensão é mais singela frente às avaliações globais dos autores mencionados. A orientação geral do texto é relatar a disseminação da pandemia em território francês. Assim, necessitamos esclarecer que, mesmo habitante de FortalezaCeará-Brasil, atualmente estamos em solo francês. No último dia 09 de março, desembarcamos em Paris e nos deslocamos para a cidade de Le Mans, no departamento de Sarthe, oeste francês. Nesta altura, a França já registrava 1412 casos confirmados, sendo 66 graves e 25 mortes de pessoas que foram hospitalizadas. No Brasil, o primeiro caso foi registrado dia 26 de fevereiro em São Paulo e, no início de março, casos foram registrados no Rio de Janeiro e no Espírito Santo. Na sequência, dia 11, a Organização Mundial de Saúde declara estado de pandemia. A partir de então, debates sobre a 
disseminação, as mortes e os confinamentos já ganhavam a pauta do cotidiano dos brasileiros e, mais ainda, dos franceses.

7 No dia 17 de março iniciou-se o confinamento social na França. De lá pra cá, acompanhamos a situação nacional e internacional a partir de um apartamento localizado na rue Gambeta, na cidade de Le Mans, inscrita no departamento de Sarthe, integrante da região Pays de la Loire. Trataremos destes espaços específicos, mas sob duas escalas e enfoques distintos. Na primeira delas, a da região, apresentaremos a evolução da doença e suas repercussões. Na segunda, a da cidade, a partir de um olhar estrangeiro recentemente instalado tentaremos apreender a difusão das notícias, os debates e, sobretudo, como a situação de confinamento afeta o cotidiano da cidade de Le Mans.

\section{Na França, na Região Pays de la Loire}

Brevemente, atrevemo-nos a apresentar características gerais da França, com destaque para sua organização administrativa territorial (pelo menos em escala regional) e informações demográficas e econômicas. No que tange à gestão do território, basicamente, a França é dividida em 18 regiões e estas estão subdividas em 101 departamentos ${ }^{5}$ (figura 1). A mais importante e dinâmica região é a conhecida île-deFrance, onde se encontra a cidade de Paris.

Figura 1. Território Francês em Regiões e Departamentos.

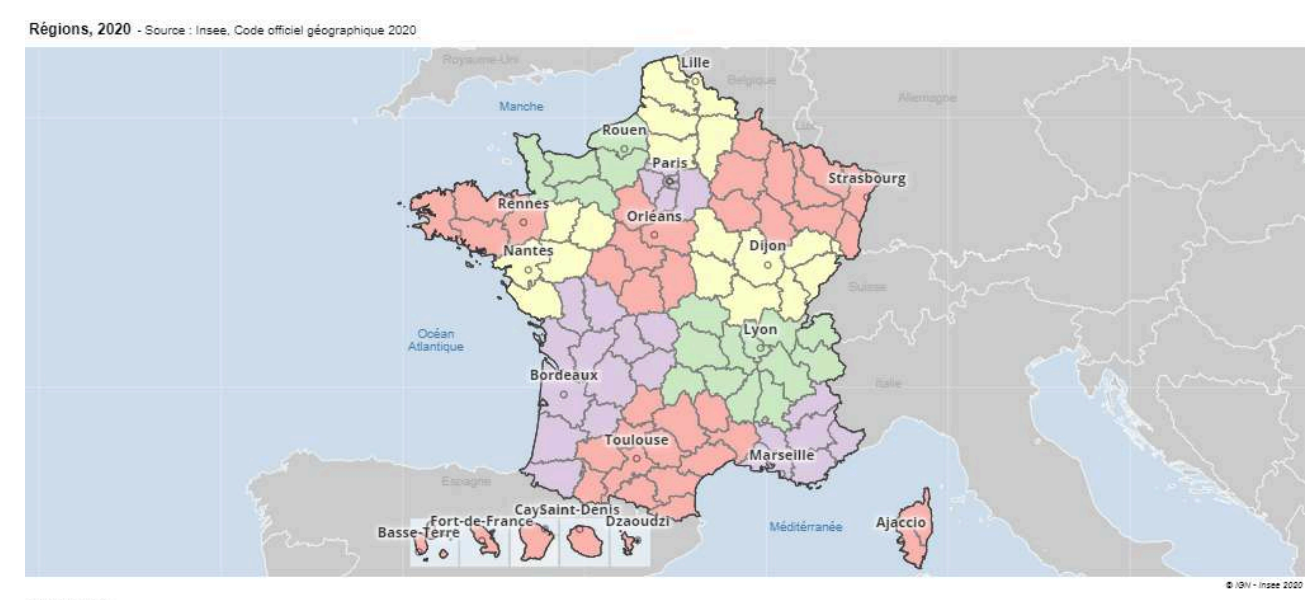

\section{Régions, 2020}

Fonte: INSEE, 2020

Em termos demográficos, dados de 2016 demonstram que a França tem população aproximada de 66,3 milhões de habitantes. As regiões da île-de-France (12,2 milhões de habitantes ou 18,3\% do total), Auvergne-Rhône-Alpes (7,9 milhões ou 11,9\%), Hauts-deFrance (6 milhões ou 9\%), Nouvelle-Aquitaine (6 milhões ou $8,9 \%$ ) e Occitanie $(5,8$ milhões ou 8,7\%) e Grand-Est (8,3 milhões) são as seis mais populosas. Pays-de-la-Loire agrega 3,7 milhões de habitante e é a $8^{a}$ mais populosa (5,6\%). (figura 2)

Da população em tela, 23,2\% apresentam idade acima de 59 anos, ou seja, 16,69 milhões. Essa informação ganha importância, sobretudo, em virtude da maior letalidade da COVID-19 em tais faixas etárias. 
Figura 2. Distribuição populacional por região, 2016.

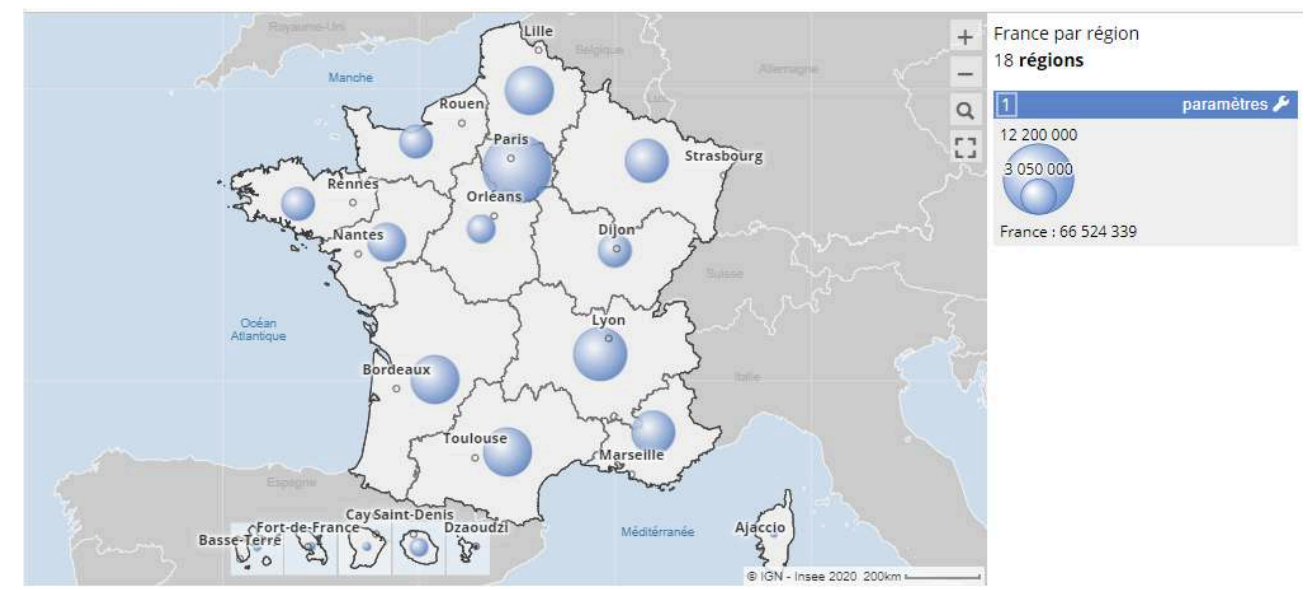

Fonte: INSEE, 2020.

11 Em termos econômicos, 73,8\% da população é considerada ativa (entre 15 e 64 anos). A taxa de desemprego atinge 14,1\%, em 2016, frente à taxa de 12,8\% em 2011 (INSEE, 2016). Para o contexto nacional, os empregos por atividades econômicas encontram a seguinte distribuição: $46,4 \%$ empregam-se em atividades comerciais, de transporte e de serviços; 32,3\% na administração pública, ensino, saúde e ação social; 12,2\% trabalham no setor industrial, $6,5 \%$ na construção e $2,7 \%$ na agricultura. 0 valor médio da hora trabalhada é igual a 25,9 euros para profissionais intelectuais com ensino superior e gerentes de empresas, 14,7 euros para profissionais de formação intermediária e, aproximadamente, de 11 euros para operários e demais trabalhadores (INSEE, 2016).

Seja pela situação geográfica, pelas condições econômicas e a distribuição da população, é prudente compreender a heterogeneidade do território. Essa diversidade pode nos ajudar a entender as diferenças no desenrolar do processo de disseminação da COVID-19.

\section{Pays-de-la-Loire e COVID-19}

13 O Pays-de-le-Loire é a sétima região de maior produção de riqueza, com PIB igual a 109.797 M€, ou seja, 5\% de participação nacional, frente aos 668.823 M€ da île-de-France (30,4\% do total) (INSEE, 2015). Loire-Atlantique, Maine-et-Loire, Vendée, Sarthe e Mayenne são os departamento a compor a região, sendo Nantes a principal cidade, seguida de Angers, Le Mans, Laval, e La Roche-sur-Yon (figura 3).

Bem servida por serviços de transportes rodoviário e ferroviário, as distâncias em relação a Paris são rapidamente percorridas. Por TGV (trens de alta velocidade), uma viagem entre Paris e Nantes dura, aproximadamente, duas horas e trinta minutos. 
Figura 3. Pays de la Loire

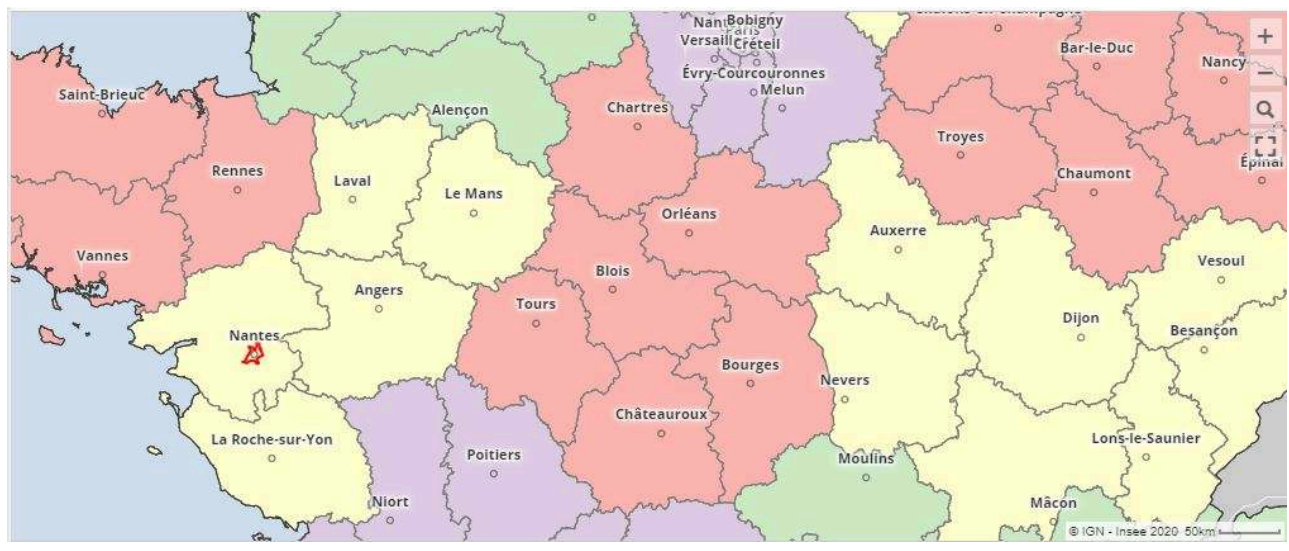

Legenda: região e seus departamentos demarcados por elipse pontilhada; Rennes (em vermelho) é a principal cidade

Fonte : INSEE, 2020

A região, banhada pela água do rio Loire e repleta de belos castelos, é um conjunto regional relativamente periférico face à dinâmica econômica e populacional de outras regiões mais ao nordeste, a leste e ao sul. Estas características apenas nos ajudam a localizar o contexto a partir do qual observaremos a pandemia.

Na França, no dia 16 de março, quando mais de 4,8 mil casos e 147 mortos haviam sido registrados, em pronunciamento em cadeia nacional o presidente Emmanuel Macron usou a metáfora da guerra para fortalecer seu discurso e conclamar seus concidadãos a confiarem nas medidas do governo central. Àquela altura, os conselheiros científicos da presidência anunciavam a onda de contaminação e a possível saturação do sistema de saúde francês. Em seu discurso à nação, o presidente anunciou o confinamento social a partir das $12 \mathrm{~h}$ do dia seguinte. Exceto supermercados, farmácias e alguns outros serviços essenciais, todas as demais empresas e instituições cessaram suas atividades. Os deslocamentos passaram a ser regulados e com necessidade de atestação de motivo. Sem isso, os agentes policiais são autorizados a multar os que infringirem as regras estabelecidas no decreto de 16 de março.

Numa democracia, medidas desta natureza não são constituídas sem críticas e efeitos controversos, sobretudo, como defende Paul Preciado, quando entendemos a imunidade como um conceito socialmente construído e atrelado a decisões políticas e ao controle social. Contudo, em linhas gerais a imprensa francesa engajou-se na campanha Restez Chez Vous ${ }^{6}$. Lógico que esse comportamento está diretamente alinhado ao avanço do número de casos severos de contaminação e às condições precárias dos sistemas de saúde italiano e, atualmente, espanhol. Mesmo os reticentes governantes do Reino Unido e dos Estados Unidos da América percebem o quanto a rapidez da contaminação e a elevação dos casos graves dependiam de condições de atendimento mais complexas.

18 A imprensa local, antes de pôr em questão o confinamento propriamente dito, fez a crítica maior ao atraso na decisão de decretar o confinamento. Os críticos relacionam este retardo aos interesses políticos frente ao primeiro turno das eleições municipais realizadas dia 15 de março, ou seja, dois antes do confinamento na França.

19 Até a primeira semana de abril ${ }^{7}$, os dados da John Hopkins University \& Medice apontava mais de 1 milhão de contaminados. EUA (245 mil), Itália (115 mil), Espanha 
(112 mil), Alemanha (84 mil), China (82 mil) e França (59 mil) lideravam o ranking do número de contaminados. Contudo, em número de mortes, impressionam os dados registrados na Itália (13,9 mil) e na Espanha (10,3 mil) (figura 4). Os grandes focos de contaminação migraram do leste asiático para a Europa ocidental e para a América sobretudo a do Norte. Contudo, os efeitos em países da África e das Américas Central e do Sul estão em plena evolução, e podemos imaginar desdobramentos mais graves face a outros problemas sociais e às deficiências nos sistemas públicos de saúde.

Figura 4. Número de contaminados por país até 03 de abril de 2020

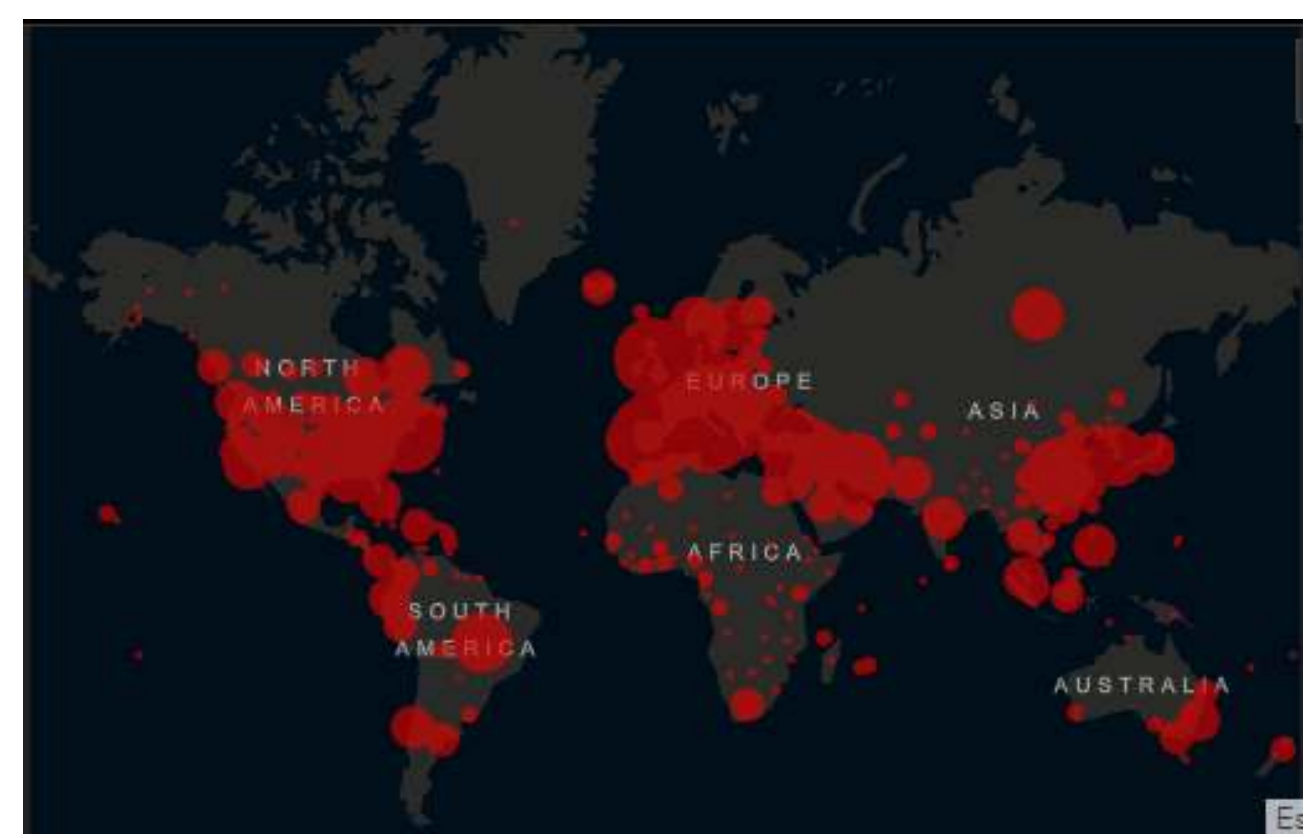

Fonte: John Hopkins University, 2020. Disponível em https://coronavirus.jhu.edu/map.html

Diante do agravamento da situação e a fim de mitigar conflitos socioeconômicos, o governo francês estabeleceu medidas paliativas, a saber: novos prazos para pagamento de tributos e impostos; remissão de impostos diretos; adiamento de pagamentos e faturas residenciais (água, gás, eletricidade); apoio econômico (auxílio de até € 1.500) para trabalhadores mais pobres, freelancers e microempresários; empréstimo garantido pelo Estado; mediação de crédito para reprogramação de empréstimos bancários; regime de desemprego parcial; mediação de empresas em caso de conflito; férias coletivas, e perdão de encargos por possível multas não pagas nas datas de vencimento. Ressalva: é necessário distanciamento temporal e aprofundamento nos números e em outras evidências para avaliar a eficácia ou não destas medidas - condições que fogem ao escopo deste escrito.

21 Por outro lado, o governo é amplamente criticado por sua ineficiência em propiciar insumos básicos para as práticas de tratamento e de prevenção de contaminação. Os exemplos mais claros são as máscaras, os testes e os aparelhos respiratórios. A impressa local (Le Monde, Le Figaro, Le Parisien) informa a ausência de máscaras inclusive para médicos e demais profissionais de saúde. O governo apelou para empresas (Slip Fracais, Les senteurs, 1083, Atelier Tuffery, Payote, Shanti K'réa, Ouvry, Guerlain, Tereos, the Bordeaux distilling company, Ibbeo, entre outras) a mudar linha de produção e ampliar a fabricação de álcool em gel, máscaras e aparelhos respiratórios. Ao mesmo tempo, no último dia 30 de março, a imprensa noticiava a chegada de milhões de máscaras 
fabricadas na China. Com o lançamento da Operação Resiliência, as Formas Armadas também foram convocadas. $O$ aumento do número de leitos se fez por organização imediata de hospitais de campanha.

Neste momento, quando se espera a chegada do "pico de contaminação", a maior preocupação diz respeito à sobrecarga dos profissionais de saúde, inclusive com crescimento do número de profissionais contaminados. A figura 5 expressa o quadro até início de abril e é possível verificar a desigualdade na distribuição regional dos casos. A região da Île-de-France é a mais afetada (10273), juntamente com todas àquelas mais a leste - Hauts-de-France [1824], Grand Est [4657], Auverge-Rhône-Alpes [2706] e Provence-Alpes-Côte d'Azur [1492]).

Figura 5. Distribuição, por região, dos casos de COVID-19 na França Metropolitana.

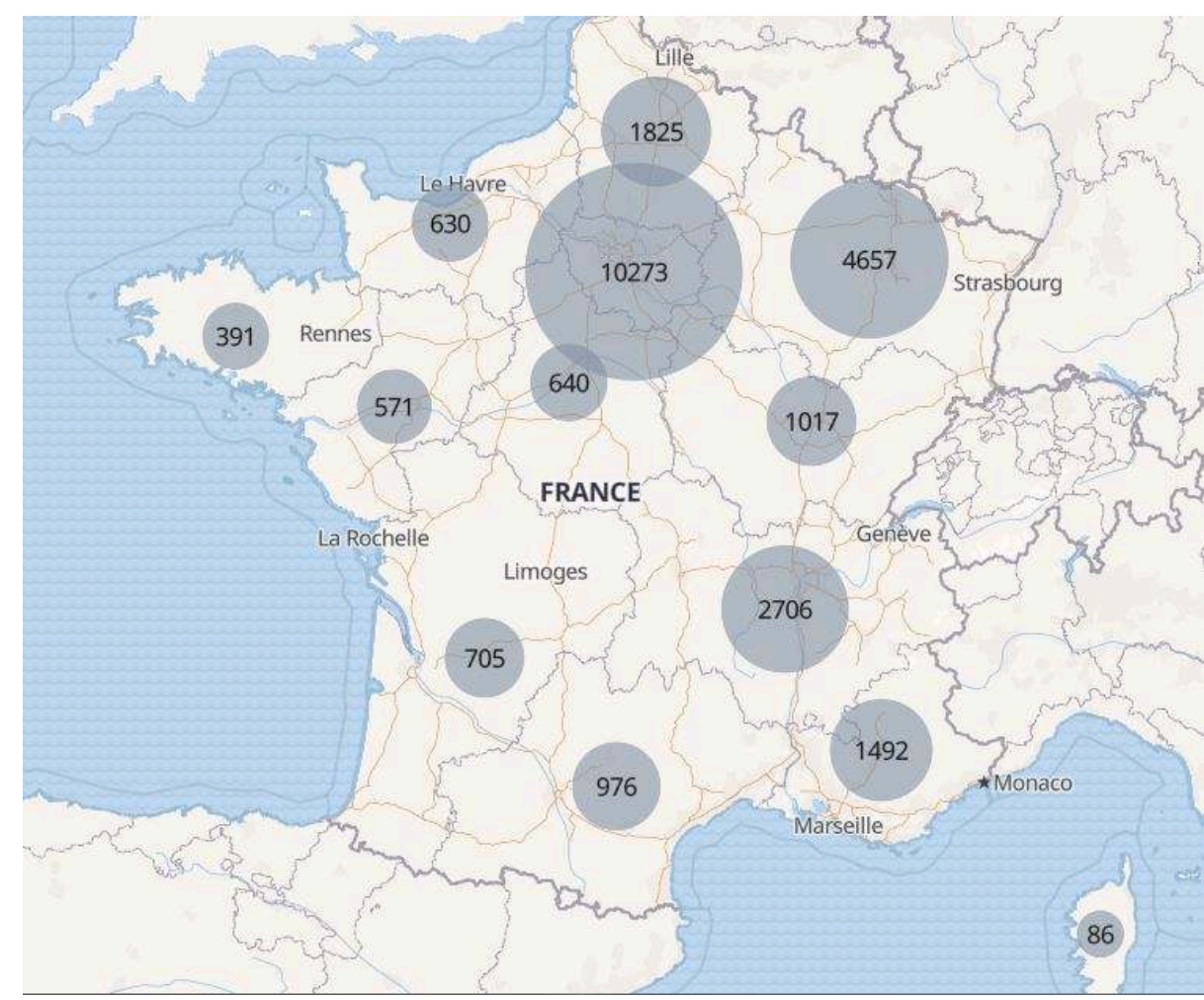

Fonte: https://www.gouvernement.fr/info-coronavirus/carte-et-donnees, 03/04/2020.

Seguindo outra lógica, as regiões mais a oeste apresentam os menores índices, a saber Bretagne (391) e Pays de la Loire (571). As regiões mais contaminadas são as com maior peso demográfico. Pensamos que a situação geográfica pode contribuir para explicar este quadro. Diferentes das mais infectadas, as regiões do oeste não são os principais nodais de atração e distribuição de fluxos do país. Da mesma forma, estão confinadas pelo oceano, sem fronteiras com outras nações. Lógico que imaginamos que o confinamento social contribui deveras para as menores taxas de contaminação.

Em termos de comparação, île-de-France conta atualmente com 2301 pessoas hospitalizadas e a utilizar aparelhos para respiração. A região Pays de la Loire, por sua vez, apresenta 141 pacientes na situação mais grave. O governo inclusive trata como principal informação não mais o número de casos absolutos, mas o número de pacientes en réanimation, posto indicar maior tendência de saturação dos equipamentos 
hospitalares. Até o dia 02 de abril, na região do Pays de la Loire, Loire-Atlantique apresentava 52 pacientes, Maine-et-Loire 40, Sarthe 22, Vendée 17 e 10 em Mayenne.

Aparenta-nos que a disseminação do caso, malgrado exceções, é mais intensa nas centralidades das redes urbanas. Mas, por quê? É a diversidade e intensidade dos fluxos e trocas com o exterior o fator decisivo para o estabelecimento inicial da epidemia. Em seguida, a própria aglomeração populacional contribui. Neste modelo, muitos dos comportamentos pessoais e coletivos tendem a espalhar o vírus (contatos diários, uso de transporte público, aglomeração em grandes centros comerciais...). Daí, os desdobramentos da epidemia variam conforme a antecipação de medidas coletivas e pessoais de confinamento e cuidados higiênicos, capacidade de testar e isolar pessoas ou áreas de maior contaminação, eficácia no modelo comunicacional e de convencimento da população e, por fim, organização dos sistemas de saúde - triagem dos casos, elevação do número de leitos e atendimento imediato dos mais graves.

Essa diferenciação regional na distribuição dos casos foi constatada e duas principais medidas têm sido executadas. A primeira consiste no convite a profissionais de saúde de espaços menos afetadas a exercerem suas funções em hospitais saturados de outras regiões. A segunda ação corresponde à transferência de pacientes em reanimação para centros hospitalares sediados em regiões com melhores condições de atendimento, visto o número de leitos vagos. A título de exemplo, TGV's adaptados (TGV Santé) foram utilizados para conduzir pacientes em estado grave para cidades como Rennes (Bretagne) e Angers (Pays de la Loire). Administradores de hospitais em Paris defendem maior integração entre os países europeus visando permitir o atendimento de necessitados em nações menos impactadas.

$\mathrm{Na}$ "guerra contra o vírus", além do confinamento, o debate nacional aponta para a cidade de Marseille e o uso da substância cloroquina no tratamento da COVID-19. o médico e cientista Didier Raoult, diretor do Instituto Mediterrâneo de Infecções, é figura reconhecida e não menos polêmica. Sua defesa da cloroquina é analisada com cuidados por outros médicos e cientistas, haja vista a ausência de pesquisas seguras e capazes de comprovar a eficácia da substância em tela e seus possíveis efeitos colaterais - como os que podem comprometer o sistema cardiovascular, por exemplo. Para este momento, porém, o médico de Marseille defende ações mais heterodoxas e faz críticas aos ortodoxos das metodologias científicas. Entre as tensões e as discussões médica, científica e ética, no dia 26 de março o governo francês acabou por autorizar a administração do medicamento.

A situação mantém-se grave ${ }^{8}$. Todavia, os debates já se encaminham para as ações em função do término do confinamento. Além da profusão do uso cotidiano de máscaras à moda asiática e da possibilidade de liberação por faixa etária, eleva-se o interesse pelo uso de sistemas de geolocalização - também utilizados em países como China e Coréia do Sul). o principio é sugerir aos usuários ("cidadãos") o uso de aplicativos para telefones portáteis e a transmissão de dados via bluetooth. Desta forma, é possível vigiar, avisar e punir pessoas infectadas/doentes que teimam em deslocar-se, detectar quais entraram em contato e por onde circularam. Há mudança na escala de acompanhamento: do confinamento físico residencial para um acompanhamento individual e em tempo real a ponto de propiciar territórios flexíveis de isolamento. Encaminha-se para o quadro destacado por Paul Preciado 9 , a saber, o corpo como fronteira. 


\section{O confinamento e as sensações a partir de Le Mans.} da cidade, são os espaços públicos por excelência (figura 6). Nas praças o fluir de gente quebra a monotonia das belas e limpas ruas secundárias e lá, de fato, sentimos a sensação de urbanidade.

Figura 6. Le Mans e seu centre-ville.

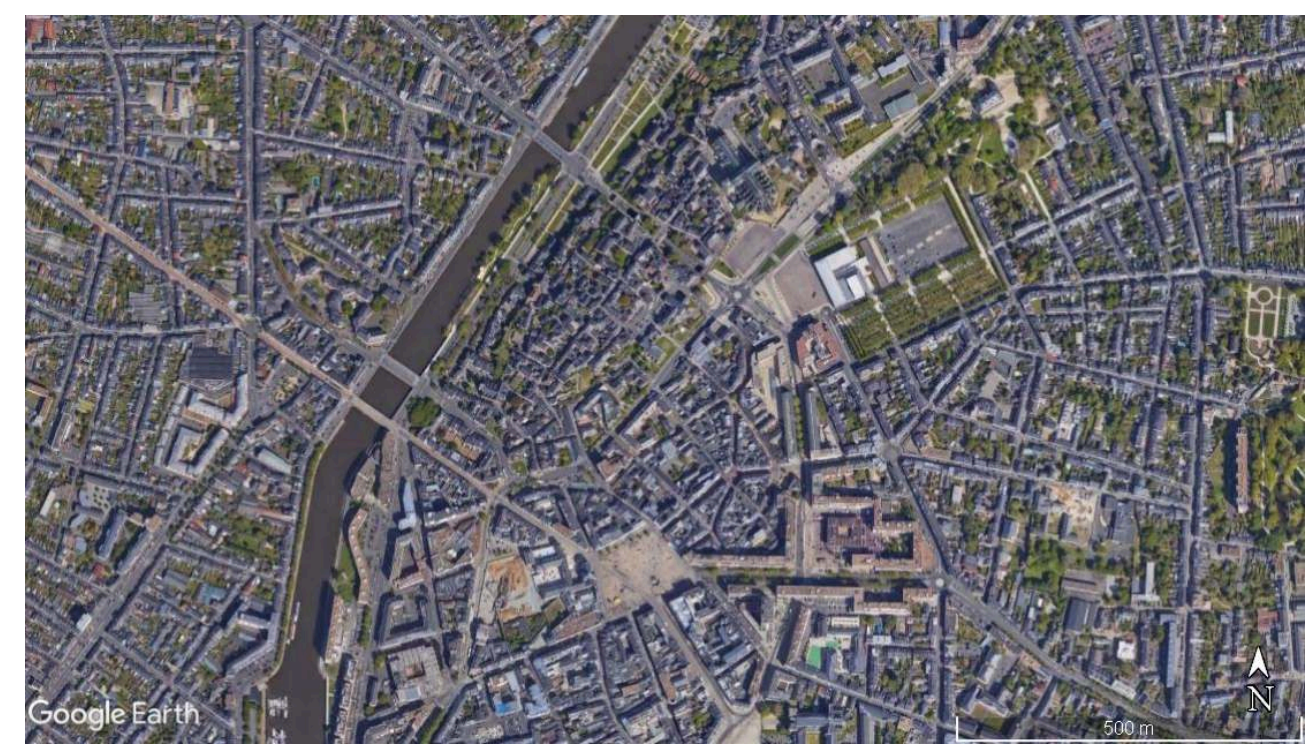

Legenda: Prace de la Republique (círculo azul); Place des Jacobins (círculo vermelho).

Fonte: Google Earth, 2020.

33 Se antes do confinamento social não pressentíamos nenhum temor ou grande atenção ao quadro nacional e internacional, hoje a situação mudou. Não constatamos pânico ou grande temor. Pensamos que se explica pelo número relativamente menor de casos e internações. Até o dia 03 de abril, Sarthe contava 18 mortes, 80 hospitalizados sem gravidade e 25 em reanimação. Nos últimos seis dias o número de hospitalizados se estabilizou (figura 7). 
Figura 7. Evolução do número de casas em reanimação do departamento de Sarthe.

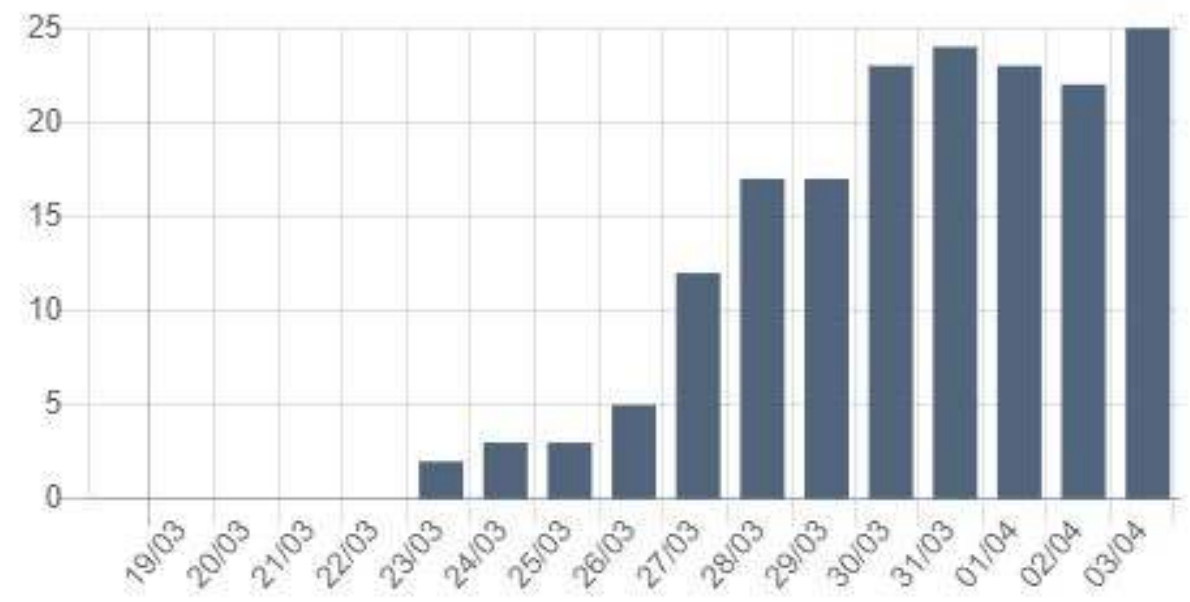

Fonte: Governo Francês. Disponível em https://www.gouvernement.fr/info-coronavirus/carte-etdonnees.

Com todas as instituições de ensino fechadas, comércios e transporte público vazios, a cidade quase pára. Da janela da rue Gambetta, vemos alguns poucos a praticar esportes, crianças em movimentos leves e felizes, senhores e senhoras numa marcha lenta e a perseguir alguns raios de sol ou com suas baguettes à mão. Mas o que mais impressiona é o silêncio. Raramente escutamos qualquer vibração sonora que lembre o burburinho de pessoas, de trânsito, de agitação (figura 8). Os debates midiáticos e o discurso médico continuam a impactar o uso do espaço público (COSTA, 2016).

Figura 8. Rua de Le Mans em período de confinamento

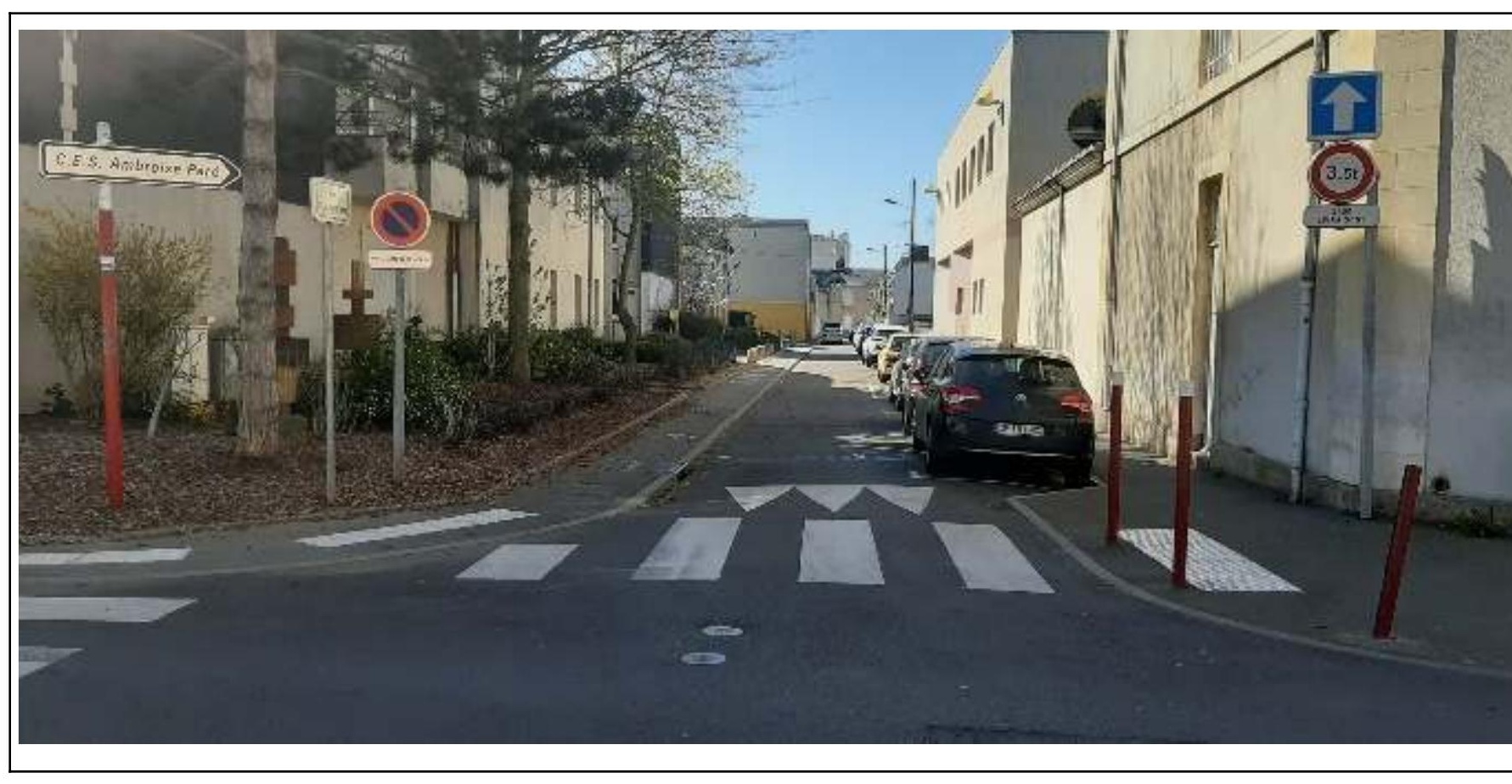

Fonte: fotografias em campo, 2020. 
Após as últimas recomendações governamentais, é perceptível a adoção do hábito do uso de máscaras. Nos supermercados há controle de entrada e filas, mas sem desabastecimento e sem correria. Lógico que a economia da cidade foi muito afetada, sobretudo os profissionais liberais e prestadores de serviços não essenciais. Neste sentido, a esperança é a flexibilização do confinamento social associada a maior controle das medidas de higiene e distanciamento cotidiano.

O medo em relação à contaminação e ao adoecimento é pensamento recorrente. Contudo, é impossível não destacar a dificuldade em incorporar a regulação do ir e vir. Quando vamos à rua por necessidade de primeira ordem, a sensação de vigilância produz desejo de retorno à residência. A qualquer momento, todos estão sujeitos à interpelação por um agente de segurança, daí a necessidade de identificação e, ao mesmo tempo, de relatar e comprovar o motivo que justifica a saída à rua.

A relação entre casa e rua ganha novo significado. Da janela, o olhar atento vislumbra a paisagem urbana ou, pelo menos, seus sub-recortes, e virtualiza os fluxos, os contatos e o vir-a-ser. Não sabemos quanto e como isso tais condições vão mudar. Por enquanto, RESTEZ CHEZ VOUS, e se munir de [cuidados e] esperança.

\section{Conclusões}

Num sistema-mundo baseado na circulação, é óbvio que bactérias e vírus rapidamente se espalham e se espalharão. A perplexidade social e as dificuldades políticas frente à pandemia atual, fazem-nos pensar como nossos sistemas pedagógicos e de comunicação são ineficazes. Dizemos isso inicialmente pela ausência de perspectiva histórica deste tipo de acontecimento e, segundo, por constatar que a avalanche de informações acessível não consegue produzir quadro educacional no qual os povos e seus governos tenham ciência das probabilidades críticas. As instituições públicas e as empresas de controle de dados não conseguem domar a produção e o impacto negativo das noticias falsas (fakenews). Em momentos de medo, epidemia e crise econômica, elas são mais avassaladoras e preocupantes.

Estes momentos nos fazem avaliar a importâncias das reflexões históricas e geográficas. No tempo e no espaço, é prudente conhecer o processo de mundialização das relações e práticas sociais e, simultaneamente, identificar as rugosidades e a "força dos lugares". Com isso, aprendemos a parametrizar a eficácia ou não de dadas ações, como por exemplo as restrições sociais, o fechamento de fronteiras nacionais, a deterioração das relações de produção e a degradação socioambiental.

Não são necessários muitos argumentos para identificar a gravidade da situação sanitária e sócio-espacial diante da expansão do COVID-19. Contudo, não cremos em mudanças generalizadas no sistema de produção e no modelo de distribuição de riquezas. Nos países do capitalismo central, pensamos que se estabeleceram ajustes na divisão internacional de trabalho - sobretudo para itens relacionados à manutenção dos sistemas de saúde e proteção. Nos países do capitalismo periférico, dificilmente vislumbramos saltos qualitativos no enfrentamento das injustiças sociais e de saúde. Muito provavelmente, com as dificuldades econômicas, medidas de austeridade serão propostas no futuro pós-epidemia.

41 Acreditamos que assim como foram produzidos aparatos legais e de controle em relação à prevenção de ações terroristas (geopolítica do medo), pensamos que governos 
como os dos países europeus (liderados por França e Alemanha) proporão novos esquemas de "segurança" biológica. Neste sentido, além dos saberes médicos, os discursos das empresas de tratamento de dados e de comunicação serão importantes para o monitoramento de cargas, substâncias e, mais ainda, de pessoas. Não sabemos se organizações como a OMS serão fortalecidas. Provavelmente, cada país ou bloco regional construirá suas regulações, métricas e procedimentos de controle. $\mathrm{Na}$ escala das pessoas e das relações cotidianas, o momento pós-crise COVID-19, ao nosso pensar, não trará novos princípios humanitários de compartilhamento e de solidariedade. Muito provavelmente, em algumas sociedades, daqui pra frente, os contatos em espaços públicos ou semi-públicos serão, consciente e inconscientemente, mais distantes e regulados, novas formas de apropriação dos espaços públicos surgirão. Por fim, no Ocidente, máscaras e luvas podem se tornar os novos acessórios de moda.

\section{BIBLIOGRAFIA}

AGBCAMPINAS. Associação Brasileira de Geógrafos - Seção Campinas. 2020. Disponível em http:// agbcampinas.com.br/site/

COSTA, M C L. A casa e a rua: objetos a medicalizar. Boletim Goiano de Geografia, v. 36, p. 197-219, 2016.

COSTA, M C L. Influências do discurso médico e do higienismo no ordenamento urbano. Revista da ANPEGE, v. 9, p. 63-73, 2013.

COSTA, M C L. O discurso higienista e a ordem urbana. 1. ed. Fortaleza: Editora UFC - Imprensa Universitaria., 2014. v. 1. 192p .

COSTA, M C L. Teorias médicas e gestão urbana: a seca de 1877-79 em Fortaleza. Hist. cienc. saude-Manguinhos, Rio de Janeiro, v. 11, n. 1, p. 57-74, Abr. 2004. https://doi.org/10.1590/ S0104-59702004000100004.

GOVERNO FRANCES. Dados e cartas - COVID-19. 2020. Disponível em https:// www.gouvernement.fr/info-coronavirus/carte-et-donnees

GUIMARÃES, R B. Saúde: fundamentos de geografia humana. $1^{\mathrm{a}}$ ed. São Paulo: Editora da UNESP, 2015. v. 1. 112p.

INSEE. Insitut Nacional de la Statisque et des Études Économiques.[2016] 2020. Disponível em https://www.insee.fr/fr/accueil.

SANTOS, M. Por uma outra globalização: do pensamento único à consciência universal. Rio de Janeiro: Record, 2006.

\section{NOTAS}

1. Vale salientar que não nos atreveremos a construir análise baseada em abordagens da geografia da saúde (GUIMARÃES, 2014). 
2. Sugerimos leitura dos textos síntese publicados por Maria Encarnação Sposito e Raul Borges Guimarães (www.revistaplaneta.com.br/por-que-a-circulacao-de-pessoas-tem-peso-na-difusaodo-coronavirus/).

3. Do grego pandemías, as; pan, "todo" + demos "povo" + ia. Doença infecciosa e contagiosa que se espalha muito rapidamente e acaba por atingir uma região inteira, um país, continente etc. Aproximamente, duzentos países registram ocorrências da doença. Para mais informações, acessar https://www.who.int/emergencies/diseases/novel-coronavirus-2019.

4. Acesse estes e outros artigos de opinião no sítio eletrônico http://agbcampinas.com.br/site/

5. Guadaloupe, Martinique, Guyane, La Réunion e Mayotte são denominados ultramarinos.

6. Tradução: "Fique em casa!"

7. Momento que finalizamos a escrita do manuscrito.

8. Eleva-se o número de mortes em retiros e casos para idosos.

9. http://agbcampinas.com.br/site/2020/paul-b-preciado-aprendendo-com-o-virus/

\section{RESUMOS}

A partir da experiência da quarentena vivida por um geógrafo brasileiro na cidade de Le Mans, apresentamos as características territoriais da França, da região do Pays de la Loire e da própria Le Mans visando compreender a difusão desigual da Covid-19. Finalmente, cremos menos em grandes transformações sócio-econômicas que em ajustes na escala das nações e nos espaços da vida cotidiana.

A partir de l'expérience de la quarantaine vécue par un géographe brésilien dans la ville de Le Mans, on présente les caractéristiques territoriales de la France, de la région du Pays de la Loire et de la ville elle-même à fin de comprendre la diffusion inégale de la Covid-19. Finalement, on croire en des mesures d'ajustement à l'échelle des nations et dans les espaces de la vie quotidienne plus qu'en des grandes transformations socio-économiques.

Con base en la experiencia de cuarentena vivida por un geógrafo brasileño en la ciudad de Le Mans, presentamos las características territoriales de Francia, la región del Pays de la Loire y la propia Le Mans para comprender la difusión desigual de Covid-19. Finalmente, creemos menos en las grandes transformaciones socioeconómicas y más en los ajustes en la escala de las naciones y en los espacios de la vida cotidiana.

Based on the quarantine experience lived by a Brazilian geographer in the city of Le Mans, we present the territorial characteristics of France, the Pays de la Loire region and the Le Mans itself to understand the uneven diffusion of Covid-19. Concerning the consequences of Covid-19, we believe less in major socio-economic transformations than in some changes in the scale of nations and the spaces of everyday life as well. 
ÍNDICE

Mots-clés: Covid-19; France; Pays de la Loire; Le Mans; quarantaine.

Keywords: Covid-19; France; Pays de La Loire; Le Mans; quarentine.

Palabras claves: Covid-19; Francia; Países del Loira; Le Mans; cuarentena.

Palavras-chave: Covid-19; França; Pays de la Loire; Le Mans; quarentena.

\section{AUTOR}

\section{ALEXANDRE QUEIROZ PEREIRA}

Professor do Departamento e do Programa de Pós-Graduação em Geografia da UFC, Laboratório de Planejamento Urbano Regional, Bolsista Pq/CNPq. Email: aqpufc@gmail.com 